\title{
Gamificação: uma nova abordagem multimodal para a educação
}

\author{
Tomás Roberto Cotta Orlandi \\ Claudio Gottschalg Duque \\ Alexandre Mori Mori \\ Universidade de Brasília - UNB, Brasil \\ Maria Tereza de Andrade Lima Orlandi \\ Universidade Católica de Brasília - UCB, Brasil
}

O RIG INAL

\section{Resumo}

Objetivo. Este artigo pretende apresentar o conceito de Gamificação como uma alternativa multimodal para a educação, considerando ser uma iniciativa relativamente recente. É um fenômeno em fase inicial, carente de maiores estudos e discussões, mas não por isso menos interessante, porquanto propõe uma nova abordagem para a educação e muitos outros segmentos do conhecimento humano contemporâneo.

Método. A pesquisa mostra que na Educação de Nível Superior, como em outras áreas, o seu uso ainda é incipiente, pois a polêmica que envolve o tema ainda é considerável, no entanto, vem conjugar esforços com outras propostas de mesma envergadura, na tentativa de sublimar alguns dos problemas de aprendizagem dos indivíduos, levando-os ao engajamento e motivação no ambiente educacional. Não se trata de uma revolução, ou proposta de abandono de conceitos e procedimentos pré-existentes, mas uma tentativa de compor com o que já existe e de aproveitar os benefícios da evolução por que passa a humanidade para que a aprendizagem se torne cada vez mais natural aos olhos dos indivíduos.

Resultados. Desafios terão que ser transpostos, podendo ser de natureza tecnológica, financeira, procedimental, educacional ou estrutural, com maiores estudos e pesquisas e avaliação dos resultados pode-se avaliar se a iniciativa é consistente e se veio para ficar.

\section{Palavras-chave}

Aprendizagem; educação; gamificação; multimodalidade; tecnologia educacional

\section{Gamification: a new multimodal approach to education}

\begin{abstract}
Objective. This article intends to present the concept of Gamification as a multimodal alternative for education, considering it a relatively recent initiative. It is a phenomenon still in its infancy, lacking in more studies and discussions, but not less interesting, since it proposes a new approach to education and many other segments of contemporary human knowledge. Method. The research shows that in Higher Education, as in other areas, its use is still incipient, because the controversy surrounding the theme is still considerable, however, it joins efforts with other proposals of the same magnitude, in an attempt to sublimate some of the learning problems of the individuals, leading them to the engagement and motivation in the educational environment. It is not a revolution, or a proposal to abandon pre-existing concepts and procedures, but an attempt to compose with what already exists and to take advantage of the benefits of evolution through which humanity passes, so that learning becomes increasingly more natural in the eyes of individuals.

Results. Challenges will have to be transposed, and may be of a technological, financial, procedural, educational or structural nature. With more studies, research, and evaluation of the results, it is possible to evaluate if the initiative is consistent and if it has come to stay.
\end{abstract}

Keywords

Education; educational technology; gamification; learning; multimodality 


\section{Introdução}

$\mathrm{Na}$ realidade contemporânea, a tecnologia, o conhecimento, a velocidade da informação, a necessidade do saber, suas formas e interações, as aspirações dos indivíduos, a organização da sociedade, pautam o estabelecimento do novo contexto mundial de educação e aprendizagem.

A educação hoje apresenta abordagens antigas e entendimentos ultrapassados, que em nada se parecem com a evolução experimentada até o presente momento em outros segmentos do conhecimento humano, como por exemplo, nas comunicações e no entretenimento. O segmento da educação deve acompanhar a evolução da sociedade contemporânea, estabelecer novos valores, procurar novas descobertas, absorver novas ideias, entendimentos e rotinas que permitam a criação de um ambiente propício para o aprendizado, delineando experiências significativas e despertando os indivíduos para o saber de forma a ajudálos no seu desenvolvimento pessoal e intelectual.

A educação experimenta hoje desafios de diversas origens, podendo ser de natureza estrutural, conceitual, pedagógica, econômica, política, financeira e social. No entanto, é recorrente a necessidade de despertar o engajamento e a motivação do estudante para o saber, para o querer saber, para o porquê saber, instigar sua curiosidade, levá-lo ao entendimento do complexo contexto onde está inserido, para que possa fazer escolhas, tomar decisões, vencer desafios com a desenvoltura desejada e ter plena consciência de sua individualidade e de suas capacidades como parte integrante de uma sociedade.

É premente que sejam concebidas e adotadas novas estratégias que tragam inovação ao ensino aplicado nas Instituições de Ensino Superior - IES, que são diretamente responsáveis pela disseminação do conhecimento, em um ambiente diversificado e complexo que é a sala de aula, considerando os ambientes presencial e virtual de aprendizagem. Surgem novas abordagens, apresentadas de vários modos alternativos aos tradicionais, como imagens, vídeos e áudios, que podem auxiliar na transmissão, absorção, retenção e transformação do conhecimento, como agentes de melhoria da estagnação do segmento.

A Gamificação surge como uma possível alternativa, que pode agregar diversos modos multimodalidade - para a captação do interesse dos alunos, o despertar da sua curiosidade, conjugando elementos que levam a participação, ao engajamento, resultando na reinvenção do aprendizado.

A Multimodalidade é a utilização de vários modos comunicativos durante uma interação entre sujeitos ou entre sujeitos e documentos. Sendo o modo, uma forma de estabelecer a comunicação e a multimodalidade se refere ao uso de mais de um modo de representação durante a comunicação (HALLIDAY, 1994).

O estímulo à interação dos estudantes com o docente, dos estudantes com o conteúdo e dos estudantes com os seus colegas é desejável um ambiente educacional dinâmico, multimodal, onde o conhecimento flui entre as quatro paredes da sala de aula de forma rápida e eficiente. Kapp (2012) define a Gamificação como o uso de mecanismos, estética e pensamento dos jogos para engajar pessoas, motivar ações, promover conhecimento e resolver problemas. Já Deterding et. al (2011) e Cunha (2014) colocam que a Gamificação pode ser resumida como o uso de elementos de jogos em contextos não relacionados com jogos.

Com o uso de elementos multimodais como desafios, regras específicas, estímulo a interatividade, fornecimento de feedback instantâneo, direto e claro e quantificação de resultados, o conceito de Gamificação adotado em parceria com outras estratégias de sala de aula propõe levar os indivíduos a uma situação favorável ao aprendizado, uma vez que o conceito é baseado em técnicas de engajamento, de aprendizado e de educação colaborativa (KLOCK, CARVALHO, GASPARINI, 2015)

Propõe ainda a nova técnica que o estudante seja lançado a uma posição de absoluta atividade perante seu próprio aprendizado, o que poderá alçá-lo a uma posição de destaque em todo o processo. Já o professor poderá participar, acompanhar, direcionar o processo de aprendizagem, e ainda interagir com o grupo de forma a garantir a transferência e absorção do conhecimento, beneficiando-se também do processo, uma vez que deverão surgir interpretações e análises diferenciadas do contexto que ele mesmo apresentou.

Trata-se, contudo, de um conceito, não de levar jogos ao ambiente de aprendizado. Propõe-se a utilização do conceito, dos valores, dos elementos multimodais dos jogos no ambiente de aprendizagem, configurando-se na tentativa de legitimação do "pensar fazendo", da prática do saber. 


\section{Referencial teórico}

A adoção do conceito de Gamificação ainda é uma proposta recente na educação, fazendo parte do rol de novas abordagens propostas para o incremento das estratégias do segmento, este trabalho tem como objetivo apresentar os conceitos de Gamificação, como uma nova abordagem multimodal para a educação, avaliar a sua aplicabilidade e de seus elementos no ambiente de aprendizagem, de nível superior, seja presencial ou virtual.

\subsection{A gamificação}

Os Games são uma realidade no mundo atual. Indivíduos de diferentes idades utilizam os games em suas vidas cotidianas, inicialmente para divertimento, revelando seu impacto no mundo de hoje. No Brasil, cerca de $23 \%$ dos brasileiros são jogadores assíduos ou casuais, o que corresponde a 45 milhões de jogadores (ORRICO,2012 apud FARDO,2013). O interesse não recai somente sobre as novas gerações, os adultos também jogam e o público que faz uso de games é considerável. Conforme Nanci (2015) cerca de $48 \%$ dos adultos acima de 50 anos jogam games, e $80 \%$ destes jogam semanalmente e $45 \%$ jogam diariamente.

Alves (2016) cita o trabalho do historiador holandês Johan Huizinga (HUIZINGA, 2000), que extrapola as relações entre jogo, história e cultura: "Para ele, a vida cultural do homem emerge a partir do jogo e não o contrário, existindo uma espécie de 'instinto do jogo'. O jogo é anterior à cultura, mas sem dúvida é recriado e ressignificado por ela" (ALVES, 2016, p. 02).

Ainda conforme Huizinga (2000), o jogo é atividade inerente do instinto natural do ser vivo de se relacionar, se divertir e se preparar para atividades complexas que acontecerão no futuro e é anterior à cultura, tendo esta evoluído para o jogo. O jogo está presente na vida dos indivíduos de todas as idades e, com seus elementos e estratégias, leva os jogadores a um objetivo único, que é a sensação de prazer resultante do alcance de uma meta, aliado ao divertimento que o processo traz (HUIZINGA, 2000).

A importância dos Games já tinha sido percebida há mais de três décadas por Papert (1994), que se tornou defensor do uso de computadores na educação como auxiliar no processo de construção do conhecimento. Na Gamificação, o jogo é deslocado da função de distração, tem seu conceito ressignificado e assume novo papel e importância na sociedade, uma vez que tem influência no desenvolvimento sensorial, psicomotor e cognitivo do indivíduo e precisa, neste contexto, ter seu papel exclusivo de distração repensado (NAVARRO, 2013).

Ainda conforme Kapp (2012 apud FARDO, 2013) o conceito de Gamificação é novo, consistente na utilização de elementos dos games (mecânicas, estratégias e pensamentos) fora do seu contexto, com a finalidade de motivar os indivíduos à ação, auxiliar na solução de problemas e promover aprendizagens.

Segundo Liu (2011), o objetivo máximo da Gamificação é incentivar o usuário de sistemas não relacionados a jogos a ter o chamado 'comportamento de jogador': foco na tarefa em mãos, realização de várias tarefas ao mesmo tempo sob pressão, trabalhar a mais sem descontentamento e sempre tentar novamente quando falhar.

Conforme Navarro (2013) as primeiras manifestações concretas da Gamificação se deram em 2010, mas o conceito já é considerado como uma estratégia de engajamento e motivação em auxílio ao processo de aprendizagem em diversos setores do conhecimento humano, características estas encontradas nos jogadores quando em interação com os games.

Como toda novidade, a Gamificação ainda necessita de maiores estudos para delimitar claramente seu alcance, conhecer seus efeitos, contextualizar suas finalidades e suas particularidades. Encontra-se na literatura os conceitos de Games, Gameful Design, Serious Games, Simuladores Virtuais e a Gamificação propriamente dita (DETERDING et al, 2011).

Para um melhor entendimento e diferenciação mais acurada, são juntadas as seguintes definições: Games são produtos de entretenimento usados para fins de lazer e recreação; Gameful Design é quando se faz uso de imagens, sons e interação que lembram games para fins de comunicação, como Game Over e Power Up; SeriousGames são jogos evoluídos e utilizados diretamente para o aprendizado; Simuladores Virtuais são softwares em 3D aliados a equipamentos imersivos de alto nível de realismo, que demonstram o impacto de decisões do indivíduo na dinâmica de uma determinada atividade, como os simuladores de direção de veículos (DETERDING et al, 2011). 
Diversas são as aplicações práticas do novo conceito de Gamificação, podendo ser exemplificadas nas áreas de Marketing e vendas (engajamento do consumidor), da Educação, da Medicina, do ambiente de trabalho das empresas, aí considerando as áreas de treinamento (treinar conceitos e competências), atendimento ao público (help desk), programas de incentivo à produtividade e outras. O mundo empresarial também está presente no mundo da Gamificação, sendo que aplica seus conceitos na elaboração de plataformas voltadas para clientes de diversas áreas do conhecimento, sendo elas treinamento e capacitação, marketing, vendas, inteligência e outras (CLEMENTI, 2014).

\subsection{A multimodalidade}

Kress e Van Leeuwen (2001) definem Multimodalidade como o uso de vários modos semióticos no projeto de um produto ou evento semiótico. Afirmam que é a terminologia comum para todos os dados semióticos. O conceito de Multimodalidade brota da Teoria da Semiótica, mais especificamente, da Semiótica Social. A Semiótica prima pelo estudo do texto, mais especificamente, focando em explicar o que o texto diz e como ele faz para dizer o que diz (BARROS, 2005). Em outras palavras, a Semiótica prima não só pelo estudo daquilo que é dito pelo texto, como também pelas estratégias textual-discursivas traçadas pelo autor do texto, a fim de exteriorizar o seu dizer. Diante disto, este campo de estudo se debruça sobre as mais distintas construções linguísticas do texto, para materializar seu dizer.

Dionisio (2011) destaca que as discussões concernentes à multimodalidade se propagaram consideravelmente. Vários pesquisadores de diversos campos de estudo: Análise do Discurso, Análise Crítica do Discurso, Análise do Discurso de Linha Francesa, Linguística Aplicada, Linguística de Texto, Pedagogia, Psicologia, Semiótica, Semiótica Social, Sociologia, tem estudado esta temática, abordando as distintas maneiras de como este conceito se materializa nas múltiplas formas da linguagem, seja escrita, oral e visual.

Xavier (2006) escreve que o texto enquanto uma prática comunicativa materializada, por intermédio das múltiplas modalidades da linguagem, tais como: verbal (escrita e oral) e não-verbal (visual). Já para Luna (2002) o texto é concebido como algo resultante da atuação das múltiplas formas da linguagem, o texto não é construído linguisticamente apenas, por meio da escrita. Ele pode se materializar através da linguagem escrita, oral e imagética, bem como da articulação e integração destas modalidades.

As tecnologias não se resumem a máquinas apenas - ganharam um novo papel, humanizado, com as preocupações da interação homem-máquina e a socialização do conhecimento (PINHEIRO, 2013). Em Capurro (2007) a Ciência da Informação nasce com um paradigma físico, depois questionado por um enfoque cognitivo idealista e individualista, sendo este por sua vez substituído por um paradigma pragmático e social. Já para Hjorland (2002), a visão sócia cognitiva tende a dar tratamento epistemológico a assuntos da psicologia no conhecimento do indivíduo numa perspectiva histórica, cultural e social.

Sob o prisma da educação, em que pese todos os recursos tecnológicos hoje disponíveis, deve ser considerado o aspecto motivacional dos alunos, considerando que determina o seu envolvimento no processo de aprendizagem. Com todos os atrativos que o mundo contemporâneo apresenta, faz-se necessário o uso de estratégias que capturem o interesse dos alunos, considerando-se também suas particularidades e qual o perfil motivacional que poderia ser aplicado. Neste contexto, a Multimodalidade tem muito a contribuir utilizando tecnologias contemporâneas, tais como vídeos, podecasts e imagens, entre outros, para motivar os alunos na sua jornada de aprendizagem.

\subsection{A construção do conhecimento na educação}

A noção de construção do conhecimento é uma ideia que têm mais de um significado, que pode ser tomada em sentidos diversos devendo ser esclarecida para poder ser melhor utilizada. Pode ser entendida como a construção de saberes universalmente aceitos em determinado tempo histórico, ou também como processo de aprendizagem do sujeito (WERNEC, 2006).

O sujeito constrói o conhecimento de acordo com o seu modo de ser e de suas capacidades, parece não haver outra alternativa. $O$ postulado que o aluno, na pedagogia tradicional, receberia passivamente os conteúdos transmitidos pelo professor é no mínimo bastante discutível, a partir da epistemologia genética de Piaget (2002). A princípio, o processo de aprendizagem se dá pela ação, qualquer que seja o método de ensino utilizado, essa aprendizagem depende da disposição do sujeito que está sendo educado e, neste caso, sendo ele um sujeito passivo, não haveria aprendizagem efetiva. 
Segundo Bzuneck e Guimarães (2008) a motivação dos estudantes para a aprendizagem é um fenômeno complexo, multideterminado, que pode apenas ser inferido mediante a observação do comportamento, seja em situações de desempenho ou de auto relato. Há que se verificar os aspectos culturais dos indivíduos e o ambiente em que o processo de Gamificação deverá ser inserido, também outro aspecto importante é considerar o erro, a frustração como molas propulsoras para enfrentar os desafios que, diferentemente da vida real, nos jogos é minimizado o erro e seus efeitos, tornando-se elemento motivador para os passos seguintes (FARDO, 2013)

Motivar o indivíduo leva a bons resultados pessoais e profissionais. Gamificar é valorizar a motivação intrínseca que enfatiza o significado pessoal, e leva à percepção do valor interno do indivíduo. Tem como base a autonomia (controle sobre sua própria vida), o domínio (fazer algo de valor por alguém ou por alguma coisa que importa) e propósito (objetivo e meta a alcançar). Segundo Deci e Ryan (2004, apud KLOCK et.al, 2014), a partir da Teoria de Autodeterminação, há três necessidades básicas da motivação intrínseca: competência, autonomia e sensação de pertencer a uma comunidade.

Conforme a desenvolvedora de jogos Jane McGonigal (2012, p.3):

Na Sociedade atual, os jogos de computador e videogames estão satisfazendo as genuínas necessidades humanas que o mundo real tem falhado em atender. Eles oferecem recompensas que a realidade não consegue dar. Eles nos ensinam, nos inspiram e nos envolvem de uma maneira pela qual a sociedade não consegue fazer. Eles estão nos unindo de maneira pela qual a sociedade não está.

Ainda segundo McGonigal (2012), no mundo virtual o indivíduo obtém a satisfação e o sucesso que almeja com mais facilidade, sendo que esta situação demonstra a importância que o mundo virtual passa a ter na vida das pessoas e, por extensão para a sociedade atual, e dessa forma, propõe a utilização de todo esse potencial e esforços para a resolução de problemas reais.

Conforme demonstrado por McGonigal (2012), na Escola, na Universidade, no seu local de aprendizagem o aluno não encontra mais o interesse e a motivação no aprendizado tradicional, estando mais próxima uma nova realidade.

Na aplicação da mecânica de jogos, Vianna et al. (2013) identificam quatro características procedentes que são essenciais para a aplicação da Gamificação que são: a meta do jogo (motivo para a realização da atividade), as regras do jogo (determinam o modo como o jogo vai ser levado e o comportamento do jogador), o sistema de feedbacks (orienta o jogador e determina a sua posição frente à meta) e a participação voluntária (implica em aceitação às demais características elencadas). Ainda, segundo os autores, outras características importantes que se relacionam para dar suporte ao processo são: narrativa, interatividade, suporte gráfico, recompensas, competitividade e ambiente virtual e outros.

A dinâmica do sistema gamificado apresenta ferramentas que prometem retorno aos usuários (ZICHERMANN e CUNNINGHAM, 2011), são elas: pontos (de acordo com o desempenho), níveis (indicam o progresso do usuário e sua qualificação), rankings (comparação entre os usuários e ajuda a visualizar o progresso individual e grupal), desafios e missões (orientam os usuários sobre as atividades que devem ser realizadas), medalhas/conquistas (representação visual de alguma realização/conquista), integração (verifica o desenvolvimento e o engajamento do usuário), loops de engajamento (relacionados à criação e manutenção de emoções motivadoras do usuário), personalização (possibilidade de transformação de itens do sistema segundo o gosto do usuário - aumenta o sentimento de engajamento , posse e controle), reforço e feedback (conferem informações sobre a localização do usuário e os resultados das ações realizadas por ele), regras (definem como será o jogo, como o usuário deve se portar, o que é permitido), narrativa (transmite informações e guia os usuários).

\subsection{A gamificação na aprendizagem}

Considerados os ambientes de aprendizagem, temos os presenciais e virtuais, e segundo Kapp (2012) o conceito de Gamificação é a definição de elementos de jogos para utilização no ambiente de aprendizagem, não significando obrigatoriamente o uso de tecnologia para o alcance de seus objetivos. Superar desafios, socializar e trabalhar por pontos são elementos que podem ser aplicados por meio de iniciativas utilizadas com 
poucos recursos, como por exemplo a recriação de rotinas já existentes, como trabalhos e atividades que visem o aprendizado com engajamento. Além disso, a aplicação do conceito de multimodalidade permite que o ambiente (virtual ou presencial) favoreça a imersão do indivíduo.

Por outro lado, existem iniciativas mais robustas que demandam a elaboração de plataformas virtuais, contratação de profissionais especializados que ajudem na elaboração do processo, onde os alunos e docentes têm a possibilidade de levar a termo o processo de aprendizagem de forma mais significativa. Klock et. al (2014) exemplificam algumas iniciativas utilizadas em ambiente AVA - Ambiente Virtual de Aprendizagem: Khan Academy é um ambiente educacional gratuito que apresenta conteúdos de matemática, física, química, biologia, economia, artes e computação, e preparatórios para exames específicos (KHAN ACADEMY, 2016); já o Codeschool é uma plataforma de aprendizado on-line que ensina diversas linguagens de programação e design para web através de vídeos e exercícios interativos (Codeschool, 2016). A multimodalidade é um conceito inerente aos ambientes virtuais, posto que quanto mais modos de comunicação, maior as chances de absorção do conteúdo pelo aluno.

Recente iniciativa do governo brasileiro foi a criação da plataforma do Enem, denominada Geekie Games, que permite ao usuário, mediante cadastro prévio, exercitar seus conhecimentos no conteúdo do Enem, acompanhar seu desempenho através de pontuação e ranking e receber dicas do que precisa ser reforçado (GEEKIE GAMES, 2016).

Outro segmento da educação que tem explorado os conceitos de Gamificação é o que trata do preparo de indivíduos para concursos, como é o exemplo do site http://www.play2pass.com.br/. Criado a partir de uma necessidade pessoal do sócio fundador, considerando o volume de material para estudo de concurso, o site conta com material de direito penal, administrativo, constitucional e outras disciplinas, cujos jogos se apresentam sob a forma de cruzadas e quebra-cabeças, remontando mapas mentais e esquemas de estudo, com atribuição de pontos e modelagem de um esquema de ranking. Segundo seu sócio fundador, atualmente o site conta com 6.000 assinaturas ativas desde a sua implementação no princípio de 2016.

No campo da educação de nível superior, as iniciativas ainda são tímidas, mas consistentes. O campo polêmico da iniciativa demonstra a instabilidade do tema, o que gera incertezas sobre a sua aplicação de maneira completa. Há que se considerar desafios tecnológicos e procedimentais que envolvem inclusive mudanças culturais muitas vezes arraigadas em raízes profundas, que demandam a revisão de comportamentos e atitudes de todos os atores do processo. No entanto, é possível antever a possibilidade de recuperação do relacionamento profícuo entre aluno e professor (MARTINS e MUNHOZ, 2014).

As possibilidades de interação (de maneira multimodal ou não) podem ser inúmeras. Alunos podem ser instados a criar jogos ou atividades gamificadas que permitam o aprendizado do conteúdo por eles e por aqueles que jogam. Os alunos podem ser chamados a incrementar um repositório de dados e informações relativas às disciplinas que têm que cursar. Outra iniciativa é chamar os alunos à elaboração de artigos e dissertações sobre determinado assunto e o resultado do seu trabalho será efetivamente publicado em livro que levará seus nomes como coautores. O estímulo ao aprendizado deve ser uma constante, o "bom ensino" deve se adiantar ao desenvolvimento, interferindo no nível de desenvolvimento potencial de um indivíduo (INHELORA, 2002, p. 11).

Outras recompensas podem ser, ainda segundo Martins e Munhoz (2016): a concessão de desconto em mensalidade, o fornecimento de ingressos para shows e cinema, materiais ou impressos, quando atividades simplificadas; no caso de atividades com plataformas próprias, poderá haver a concessão de bonificações e recompensas diretamente ligadas às atividades desenvolvidas. Nestes casos a aprendizagem acontece como uma consequência natural de seus esforços, a partir de ações intencionais e comprometimento. $O$ desenvolvimento de um processo de gamificação não exige a busca da perfeição lúdica, mas sim de um cuidadoso trabalho de planejamento prévio, por parte de professores e profissionais especializados, pois as variáveis são muitas e o processo para estabelecer missões com objetivos educacionais é uma tarefa revestida de complexidade.

A Gamificação, em qualquer campo de aplicação, também tem seus críticos. A Bringham Young University concluiu após estudos que a Gamificação e seus conceitos trouxeram incremento iniciais em níveis de motivação, no entanto não representaram significativos avanços em níveis de real capacidade e engajamento dos indivíduos ao longo do tempo, conforme o BYU News (BRIGHAM YOUNG UNIVERSITY, 2014). O pesquisador da University of Hamburg, Sebastian Deterding alertou que a Gamificação pode criar um sentimento artificial de sucesso, podendo ainda encorajar comportamentos indesejáveis (DETERDING, 2011). Segundo 
ele, considerando a competição e o encorajamento para o surgimento de líderes, problemas podem surgir como comportamentos antiéticos e falta de colaboração.

O entendimento inicial de que os Games são utilizados para o entretenimento também gera resistências entre profissionais da educação que entendem que desvirtua o foco do engajamento e da aprendizagem, estando carente da seriedade necessária, não resultando no sucesso que é prometido pelos defensores do novo conceito.

A Gamificação surge como uma proposta educacional de abordagem multimodal que visa fortalecer o processo de aprendizagem, pretendendo despertar o interesse, a curiosidade e a participação nos indivíduos, e ainda utilizar elementos modernos e prazerosos para a realização de tarefas e a conquista de objetivos. Deverá ser precedida de planejamento, capacitação, pesquisa e acompanhamento para que seja iniciativa consistente, agregadora e resulte enriquecedora nos diversos segmentos da realidade contemporânea, na educação, promovendo a motivação, o engajamento e a participação dos usuários no processo, observados seus perfis e aspectos culturais, o contexto onde estão inseridos e os objetivos do processo.

Segundo Freire (2002, p.82 e 83), “(...) o jogo não deixa esquecer o que foi aprendido... faz a manutenção do que foi aprendido... faz com que o jogador se prepare para novos desafios".

Nesse contexto, a Gamificação, como uma abordagem multimodal, deve contribuir com o grande descompasso existente entre a educação e o mundo contemporâneo e a sua cultura digital, que tanto influencia a sociedade, uma vez que a pulverização do conhecimento e das múltiplas formas de obtê-lo, levam a necessidade de repensar o ensino, reestruturar as regras existentes e rever paradigmas arraigados e conservadores sem perder de vista os objetivos da educação e sem deixar-se influenciar pelos extremos, causados pela distância ou proximidade excessiva do mundo digital.

\section{Metodologia da pesquisa}

Esse trabalho é classificado como pesquisa exploratória, no ponto de vista dos objetivos (GIL, 2010), pois visa proporcionar maior familiaridade com o problema com vistas a torná-lo explícito. Envolve levantamento bibliográfico, entrevistas com pessoas que tiveram experiências práticas com o problema pesquisado. Segundo GIL (2010), uma pesquisa exploratória envolve: pesquisa bibliográfica, entrevistas com pessoas que tiveram, ou tem, experiência prática com o problema pesquisado. Pesquisas exploratórias visam proporcionar uma visão geral de um determinado fato.

Ainda em GIL (2010), a pesquisa exploratória é realizada sobre um problema ou questão que geralmente possui pouco ou nenhum estudo anterior a respeito. O objetivo desse tipo de estudo é procurar padrões, ideias ou hipóteses. A ideia de pesquisa exploratória, não é testar ou confirmar uma determinada hipótese e sim avaliar quais teorias ou conceitos existentes podem ser aplicados a um determinado problema.

Para a composição do trabalho, foi adotada a pesquisa exploratória, auxiliada pela utilização de questionários dirigidos a acadêmicos que estudam o assunto Gamificação na Educação. Devido à variada gama de aplicações a que pode ser submetida o conceito de Gamificação e seus elementos, obteve-se a participação de diversas especialidades em resposta aos questionários encaminhados, dentre eles: uma doutora desenvolvendo um trabalho de Pós-Doutorado em Educação e Tecnologia, cujo escopo do trabalho é o desenho instrucional de atividades gamificadas para cursos à distância; um mestre em Educação, desenvolvendo um trabalho acadêmico no Curso Design de Tecnologias Digitais, com escopo em fotografia, criação e edição de imagem digital, modelagem e animação 3D e produção de jogos digitais; e um especialista em Engenharia da Computação desenvolvendo um trabalho de Mestrado, cujo escopo é a integração de um modelo de Gamificação em um ambiente virtual de aprendizagem.

Também foi levada a termo entrevista com empresário e fundador do site play2pass, que respondeu a perguntas acerca da forma como o site foi concebido e modelado, qual o público que se propõe aderir ao programa e os primeiros resultados encontrados. O estudo foi aprofundado da literatura existente e contou ainda com a análise das conclusões geradas por aqueles que acumulam experiência no campo da Gamificação dentro do segmento da Educação, considerando também a existência de farto material em estudos fora do referido segmento.

O período abrangido pela pesquisa iniciou em abril/2016, e se estendeu até agosto/2016, com textos de pesquisadores e profissionais de ensino de universidades brasileiras, e também de instituições de ensino 
internacionais, os quais publicaram pesquisas em assuntos relacionados à Gamificação com contribuições de relevância para a pesquisa. Nessa pesquisa, foram considerados os autores que abordaram a Gamificação como possível alternativa multimodal para o fortalecimento do processo de aprendizagem, com foco no interesse e participação dos alunos, assim como foram apresentadas as manifestações dos críticos do assunto, tendo em vista tratar-se de conceito novo e pouco explorado no formato apresentado, nos meios acadêmicos até o presente momento.

Compreender a iniciativa em sua plenitude revelou-se uma premissa para o desenvolvimento do artigo, tendo como base o momento atual, a partir de teorias educacionais pré-existentes, conforme Papert (1994) e Huizinga (2000), abordagem multimodal definida por Kress e Van Leeuwen (2001), e o entendimento dos novos pesquisadores, como Kapp (2012) e Deterding (2011), acerca da Gamificação nesse novo contexto imposto pela cultura digital à sociedade.

\section{Achados da pesquisa}

As pesquisas realizadas apontam para aspectos positivos da Gamificação em ambientes educacionais, no entanto com a devida cautela, conforme a seguir evidenciado pelos pesquisadores consultados. Da variada gama de aplicações a que pode ser submetido o conceito de Gamificação e seus elementos, obtivemos a participação dos pesquisadores, conforme tabela 1, que apresenta os perfis dos participantes.

Tabela 1 - Perfil dos pesquisadores

\begin{tabular}{c|l}
\hline Pesquisador & \multicolumn{1}{c}{ Perfil } \\
\hline 1 & $\begin{array}{l}\text { Doutora desenvolvendo um trabalho de Pós-Doutorado em Educação e Tecnologia, cujo escopo do } \\
\text { trabalho é o desenho instrucional de atividades gamificadas para cursos à distância }\end{array}$ \\
\hline 2 & $\begin{array}{l}\text { Mestre em Educação, desenvolvendo um trabalho acadêmico no Curso Design de Tecnologias Digitais, } \\
\text { com escopo em fotografia, criação e edição de imagem digital, modelagem e animação 3D e produção de } \\
\text { jogos digitais }\end{array}$ \\
\hline 3 & $\begin{array}{l}\text { Especialista em Engenharia da Computação desenvolvendo um trabalho de Mestrado, cujo escopo é a } \\
\text { integração de um modelo de Gamificação em um ambiente virtual de aprendizagem }\end{array}$ \\
\hline
\end{tabular}

Fonte: Elaboração Própria

- Todos os entrevistados aplicariam o conceito de Gamificação apenas em sala de aula de Graduação;

- Todos os entrevistados propõem uma atividade de Gamificação que abranja todo o semestre;

- Todos os entrevistados assinalaram os elementos desafios e feedbacks como mais atraentes;

- Todos os entrevistados apontaram que verificar o nível de engajamento e participação dos alunos, avaliar a sociabilidade e espírito de grupo dos alunos são melhores formas de avaliação dos resultados;

- Todos os entrevistados concluíram que as seguintes palavras-chave definem a Gamificação: ludicidade, performance e engajamento;

- 2/3 dos entrevistados incluíram também dinamismo, aprendizado, interação, conhecimento, diversão, inovação, participação, estímulo e prática no grupo de palavras-chave que definem a iniciativa, conforme demonstrado no gráfico 1. 
Gráfico 1 - Definição de gamificação

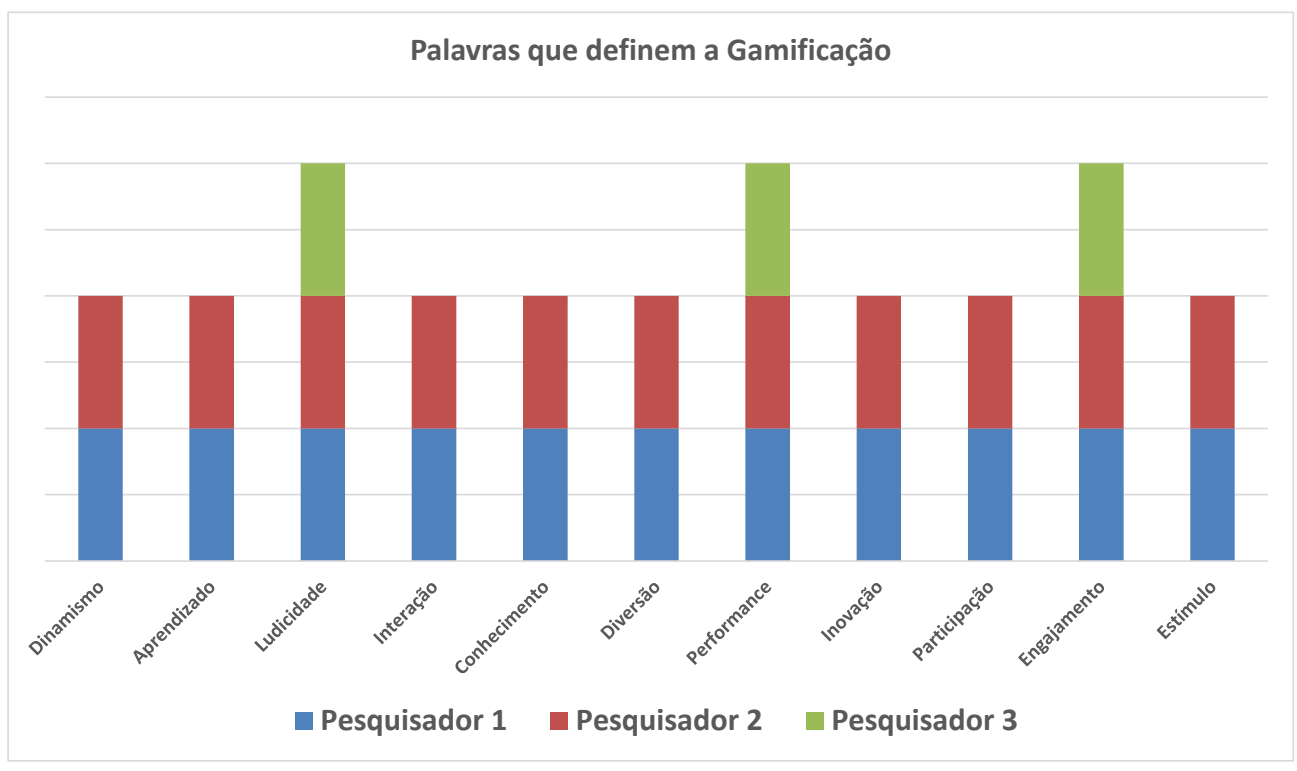

Fonte: pesquisa desenvolvida pelos autores

Observa-se que, quando perguntados: "Segundo sua percepção, a aplicação da Gamificação no segmento da Educação é bem aceita? ": 66\% dos entrevistados responderam "nem sempre" e 33\% responderam "sim", resultado este que pode indicar que nos dias de hoje ainda existem resistências ao uso da Gamificação na educação.

Conforme apresentado no Gráfico 2, quando indagados se recomendariam a Gamificação: $33 \%$ responderam "Recomendo Fortemente", 33\% responderam "Recomendo" e 33\% responderam "Recomendo Parcialmente". Esses posicionamentos indicam a necessidade de cautelas para a adoção da iniciativa, devido às dúvidas existente sobre a iniciativa e seus efeitos, bem como à diversidade de sua aplicação.

\section{Gráfico 2 - Recomendação da Metodologia}

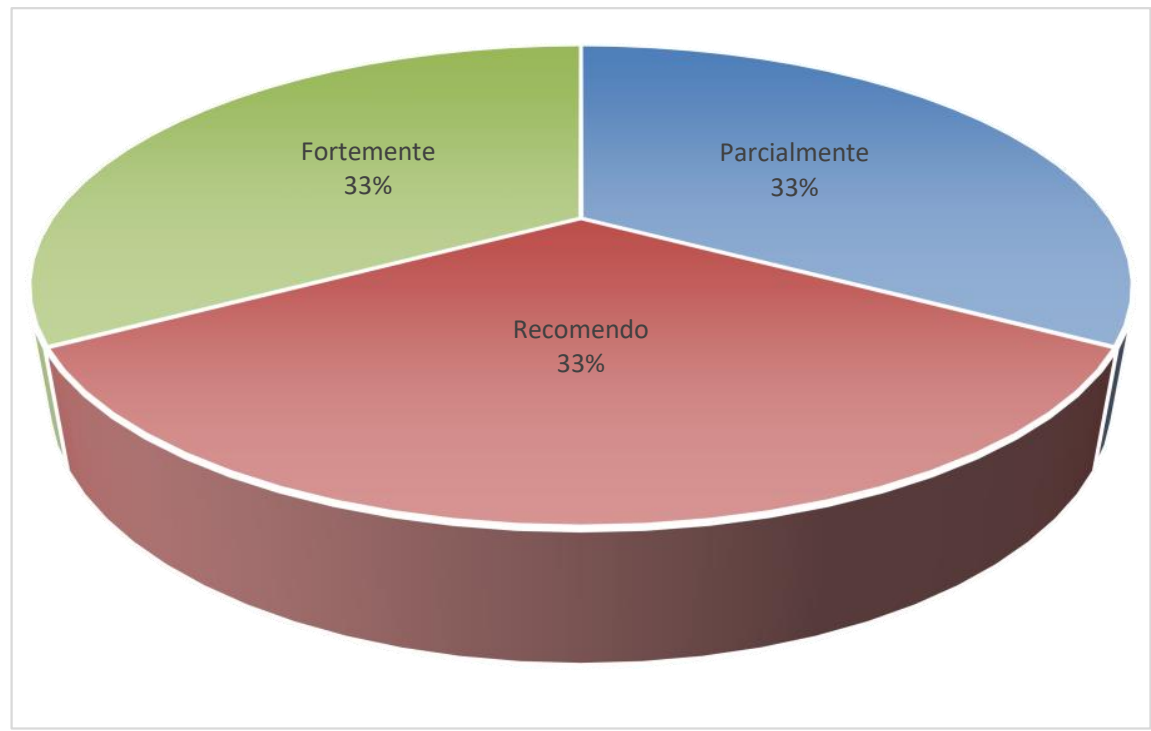

- Pesquisador 1 - Pesquisador 2 - Pesquisador 3 
Ressaltam-se as limitações da pesquisa, considerando que, do total de solicitações aos pesquisadores de informações acerca do tema, mediante resposta do questionário elaborado para este fim, somente a metade dos requeridos respondeu. Nesse contexto, a iniciativa apresenta-se com potencial para o ambiente da educação, visto que nos questionários respondidos pelos pesquisadores, pode-se apurar que 100\% aprovou as seguintes iniciativas: uso da Gamificação apenas para Graduação; extensão da atividade para o semestre da disciplina; elegeu os elementos da Gamificação - os desafios, o feedback como mais atraentes; escolheu a verificação do nível de engajamento e participação dos alunos e a avaliação da sociabilidade e espírito de grupo dos alunos como melhores formas de avaliação de resultados. No entanto, nota-se um cuidado quanto ao uso da Gamificação na educação, considerando as resistências hoje existentes no campo educacional e a recomendação encontrada na pergunta - Recomendaria a Gamificação? - conforme consignado nas respostas apresentadas.

\section{Primeiros resultados}

O estudo da Gamificação como uma alternativa multimodal de ensino, ainda é relativamente novo. Ficou evidenciado que a sua utilização prática ainda é tímida, considerando os possíveis desdobramentos do tema. Outro fator a se considerar é que o assunto apresenta uma diversidade considerável de aplicações, dentro e fora da educação, e, tendo em vista ambientes educacionais, apresenta-se factível de aplicação em diferentes esferas de ensino (básico, médio, superior, pós-graduações stricto e lato sensu), nos ambientes presencial e virtual.

Os elementos da Gamificação não seguem uma regra ou um padrão, sendo que podem ser aplicados em sua totalidade ou parcialmente; podem requerer recursos financeiros ou apenas a remodelagem de procedimentos já existentes, sem que isso signifique custos adicionais; podem abranger todo um período de semestre, ou apenas um curto período pré-determinado; podem significar uma atividade ou apenas um projeto; podem resultar em tarefas teóricas ou procedimentos práticos a serem alcançados; podem ser aplicados em ambientes virtuais ou presenciais de aprendizagem; tudo vai depender da finalidade, dos recursos disponíveis, tanto humanos, quanto financeiros, como pedagógicos, do apoio da Instituição de Ensino e outras variáveis a serem consideradas, visto que o conceito tende a redefinir o processo de aprendizagem, resgatando o interesse e a participação com vistas ao crescimento intelectual.

Individualmente, a interação constante com os elementos multimodais de um game pode envolver o indivíduo de tal forma que ele deve estar atento a uma quantidade significativa de variáveis dentro de um mesmo contexto, situação que pode provocar transformações no seu sistema cognitivo. Observa-se que os games e seus elementos carregam consigo estímulos, intrínsecos e extrínsecos, multimodais e rápidos, característicos da cultura digital a que estamos submetidos. A psicologia envolvida na Gamificação tem que ser observada, uma vez que lida com os indivíduos e um perfil todo próprio a ser considerado.

A utilização de elementos multimodais de games em sala de aula, virtuais ou presenciais, também requer que os docentes estejam aptos à iniciativa, uma vez que a capacidade didática do docente tende a se desenvolver para acompanhar o ritmo das novas atividades. A formação de docentes com capacidade para lidar com esse novo contexto cultural é uma necessidade, uma vez que terão que lidar com tecnologias e recursos digitais, que se renovam a cada momento. Devem, inclusive, estar preparados para conhecer a nova linguagem utilizada, dos recursos digitais e dos alunos, para que possam melhor conduzir o ambiente de aprendizagem que está sob seu controle. Em outras palavras, eles precisam imergir nos ambientes semióticos que entrelaçam a presença das tecnologias da sociedade contemporânea (FARDO apud ALVES, 2008).

\section{Discussão}

A proposta desse artigo visa apresentar o conceito Multimodal de Gamificação na Educação e seus desdobramentos, considerando a necessidade do segmento de se modernizar e oferecer aos indivíduos uma educação moderna, de qualidade, interessante e envolvente, que consiga atrair o interesse e os esforços com vistas ao sucesso do processo. Por outro lado, apresenta-se como essencial que os docentes sejam convenientemente preparados para isso, esclarecidos quanto aos mais variados métodos, capacitados para a correta utilização e avaliação dos resultados. Isso deve diminuir resistências e pré-conceitos quanto à adoção do tema nas Instituições de Ensino. No entanto, o conceito ainda necessita de maiores estudos decorrentes de aplicações práticas, uma vez que na vai-se lidar diretamente com os indivíduos e seus mais variados perfis, 
capacidades e objetivos. Não é um processo linear, mas permeado de problemas e alternativas, dessa forma apresenta-se como uma proposta que deve ser cuidadosamente planejada e preparada.

Considerando esses cuidados, Fardo (2013) alertou que a Gamificação precisa ser mais estudada e compreendida, tendo em vista não só o fato de ser assunto bem recente, mas também, estar em discussão em vários setores da Sociedade, inclusive entre pesquisadores não só da área de Educação, mas de todas as áreas do conhecimento, para as quais a iniciativa se apresenta como aplicável. A professora Ruth Clark (CLARK,2013), especialista em desenho instrucional e treinamento em tecnologia, Doutora em Psicologia Educacional e Tecnologia Instrucional da University of Southern California, afirmou que games não ensinam. Argumentou a professora que os games precisam estar alinhados com os objetivos instrucionais e oferecerem o correto equilíbrio entre o desafio e a orientação, para no fim atender ao objetivo de aprendizado. Este posicionamento foi rebatido pelos pesquisadores Kapp, Blunt, Conolly, et al., Hays e Sizmann (KAPP,2013) quando afirmaram que os games ensinam e impactam positivamente na motivação dos indivíduos e que no final não seria o veículo levando o conhecimento que faria a diferença, mas o design, o design motivacional. Instruções bem delineadas e games bem elaborados causam um poderoso impacto nos indivíduos. Segundo os pesquisadores o debate deveria recair sobre os melhores elementos de games a serem utilizados para criar os melhores games para os estudantes (KAPP, 2013). Fica claro que o assunto ainda é objeto de controvérsias mesmo entre renomados pesquisadores, dada a sua vasta aplicabilidade no contexto do conhecimento Contemporâneo e os ainda desconhecidos efeitos decorrentes de sua disponibilização.

Dessa forma, a Gamificação visa a potencialização do ensino e da aprendizagem, com foco na resolução ou atenuação de problemas que envolvem o interesse e participação dos alunos e evolução dos docentes no processo educativo. Considera-se que o ser humano tem, em sua natureza, o instinto pelo jogo (HUIZINGA, 2000), que com o passar dos anos, vem sendo ressignificado e assumindo novo papel na Sociedade, pois exerce grande influência no desenvolvimento cognitivo, sensorial e psicomotor do indivíduo (NAVARRO, 2013). A Educação perpetua e dissemina o conhecimento, e ao mesmo tempo promove o seu desenvolvimento, garantindo assim a continuidade da sociedade humana. Observando os indivíduos em seus mundos virtuais, ou mundo dos games, pode-se perceber o quão interessados, engajados, animados são seus esforços para o atingimento de objetivos e metas; e por livre e espontânea vontade. Pergunta-se qual a melhor forma de levar essa situação para a vida real, aproveitando esses esforços para as situações reais da vida dos indivíduos (McGONIGAL, 2012). No entanto, há que se considerarem as variáveis que envolvem a iniciativa, em especial o perfil dos alunos e docentes, sem falar nos aspectos estruturais e financeiros, por exemplo, externos ao contexto, mas indispensáveis para a sua continuidade.

\section{Considerações finais}

A formulação do objetivo do artigo foi determinante para o planejamento e a formulação de diretrizes da pesquisa com vistas à sua formatação. Os questionários foram dirigidos a pesquisadores em contato com 0 novo conceito, dentro de suas esferas de atuação, buscando a coleta objetiva de dados e impressões de atores do novo processo, pesquisadores, docentes e alunos. Dentro do contexto educacional de ensino superior, como sugestão para utilização em trabalhos acadêmicos futuros, restou claro que haverá a necessidade de maiores estudos na área, o que motivará a ampliação da pesquisa com possibilidade de elaboração de questionários dirigidos especificamente a docentes e discentes que sejam atores de um processo de Gamificação.

Faz parte da cultura do ser humano jogar, brincar, sendo natural se divertir. Ressignificar o jogo, deslocando-o da função de distração e divertimento para tarefas mais complexas. Trata-se de uma atividade imersiva, envolvente e multimodal, que a todo momento se conecta ao indivíduo. A Gamificação propõe um novo olhar sobre a motivação dos indivíduos, instando-os a um maior engajamento e interesse no processo de aprendizagem. Como dito anteriormente, passados os anos, a educação foi um segmento do conhecimento humano que ainda não aproveitou as boas iniciativas do seu desenvolvimento social e tecnológico. Conceitos mudaram, paradigmas foram quebrados, as novas gerações são diariamente submetidas a um fluxo ininterrupto e rápido de informações, como nunca antes experimentado. Há que se reconquistar os alunos, modernizar o processo de aprendizagem, demonstrar a importância do conhecimento, comunicar-se com ele por meio dos vários modos de comunicação. Como fazer para trazer um indivíduo que abriu os olhos num mundo de novos comportamentos e novas oportunidades, inclusive tecnológicas, para um ambiente de aprendizagem interessante, envolvente e prazeroso? Como a Educação pode acompanhar esse desenvolvimento, sem perder a sua essência, a sua finalidade, e ao mesmo tempo valorizar e incentivar o processo. 
Não se trata de um rompimento, mas de uma proposta de auxílio, conjugação de esforços, e de trabalho direcionado ao desenvolvimento dos indivíduos. Eles são o objetivo do aprendizado, o sucesso deles é o sucesso do sistema educacional. Para tanto, qualquer iniciativa de Gamificar significa pesquisar, prestar atenção nos objetivos delineados, ouvir os agentes do processo, docentes e alunos, direcionando esforços para a resolução de problemas, para o exercício constante da criatividade, assim suplantando problemas e resistências à nova ideia. As diferentes faces da Gamificação demonstram a pluralidade de aplicações possíveis, em ambientes com ou sem recursos, sendo eles financeiros, estruturais, educacionais e muitos outros. A Gamificação pode fazer uso de plataformas novas e recursos caros, no entanto, pode significar também a simples aplicação de apenas alguns elementos multimodais de games nas atividades diárias de estudantes, instando-os ao saber, às novidades do conhecimento, à participação, ao engajamento, ao prazer em aprender. Nas Instituições de Ensino Superior a iniciativa ainda é tímida, sendo mais encontrada em empresas da esfera privada, direcionada também ao aprendizado, só que de cunho empresarial. Também é um conceito que está sendo objeto de estudo e avaliação por parte de pesquisadores do Brasil e do exterior.

Para alcançar os objetivos esperados, os agentes do novo conceito, para sua efetividade, terão que observar o objetivo proposto, suas características, a amplitude a ser alcançada, o público a ser direcionado e uma gama considerável de variáveis, intrínsecas e extrínsecas, não esquecendo que se trata aqui de potencializar aprendizagem, motivar indivíduos, mexer com aspectos psicológicos individuais e perfis diferenciados. Em resumo, sua aplicação tem que ser precedida de levantamentos, estudos, planejamento detalhado, aplicação consciente, acompanhamento e avaliação.

Como conceito novo, a Gamificação como uma abordagem multimodal para a educação, ainda se reveste de uma áurea de desconfiança e insegurança em alguns setores, sendo assunto ainda verdadeiramente polêmico, dadas as discussões existentes entre os diversos pesquisadores do tema. Entretanto, a pesquisa, a discussão e o estudo são preponderantes para que a iniciativa venha a ser analisada e seus resultados bem avaliados, para que no futuro possa sustentar e justificar a sua adoção, com credibilidade e confiabilidade. Com os cuidados necessários, observados os limites individuais, lançando mão de um acurado planejamento, estabelecimento claro de objetivos a serem alcançados, a iniciativa pode ser positiva. Pesquisas e estudos ainda são necessários para a evolução do tema, a disseminação de seus elementos e efeitos em todos os segmentos da Educação, para que se gere discussão e aprofundamento. Perguntas têm que ser respondidas. Somente assim, pode-se chegar a uma avaliação real dessa nova estratégia que vem com propósitos positivos e alinhados com a cultura digital do Século XXI. Dentro do contexto educacional de ensino superior, como sugestão para utilização em trabalhos acadêmicos futuros, restou claro que haverá a necessidade de maiores estudos na área, o que motivará a ampliação da pesquisa com possibilidade de elaboração de questionários dirigidos especificamente a docentes e discentes que sejam atores de um processo de Gamificação.

\section{Referências}

ALVES, A.M.P. Cultura lúdica sempre acompanhou a humanidade. Revista Pré-Univesp, 59. Julho 2016. Universidade de Maringá. Disponível em: <https://pre.univesp.br/cultura lúdica\#v9qsowvbnos> Acesso em 10.jan.2018.

BARROS, D. L. P. Teoria semiótica do texto. São Paulo: Ática, 2005.

BRIGHAM YOUNG UNIVERSITY. Playing Hunger games: Are gamified health apps putting odds in your favor?, 2014 . Disponível em <https://news.byu.edu/news/playing-hunger-games-are-gamified-health-apps-putting-odds-your-favor>. Acesso em 10.jan.2018.

BZUNECK, J. A.; GUIMARÃES, S. É. R. - RUFINI, S. É. R. A promoção da autonomia como estratégia motivacional. In: BORUCHOVITCH. E; BZUNECK, J. 2008.

CAPURRO, R. Epistemología y Ciencia de la Informacíon. EnI@ce: revista Venezolana de Informacíon, Tecnología y Conocimiento, año 4, n.1, Enero-Abril, p. 11-29, 2007.

CLARK, R. Why Games don't Teach. Learning? Solutions Magazine. 2013. Disponível em:<https://learningsolutionsmag.com/articles/1106/why-games-dont-teach>. Acesso em 10.jan.2018.

CLEMENTI, J.A. Diretrizes Motivacionais Para Comunidades De Pratica Baseadas Na Gamificação, 2014 - Disponível em: $<$ https://repositorio.ufsc.br/xmlui/bitstream/handle/123456789/128683/328203. pdf? sequence $=1$ \&is Allowed $=y>$. Acesso em 10.jan.2018.

CODESCHOOL, Site Oficial. Disponível em:<https://codeschool.com> Acesso em 10.jan.2018. 
CUNHA, L. F. da. Modelo conceitual para a gamificação em ambientes e-learnig e sua utilização no AdaptWeb. Trabalho de conclusão de curso (Bacharelado em Ciência da Computação) Universidade do Estado de Santa Catarina, Joinville, 2014

DECI, E. L.; RYAN, R. M. The "what" and "why" of goal pursuits: human needs and the self-determination of behavior.

Psychological Inquiry, v.11, n.4, p.227-268, 2000.

DETERDING, S., KHALED, R., NACKE, L., DIXON, D. Gamification: Toward a Definition, CHI 2011 Gamification Workshop Proceedings, Vancouver, BC, Canada, 2011.

DIONISIO, A. P. Gêneros Textuais e Multimodalidade. KARWOSKI, A. M.; GAYDECZKA, B.; BRITO, K. S. (Org.). Gêneros textuais: reflexões e ensino. São Paulo: Parábola Editorial, 2011.

FARDO, M. L. A Gamificação como método: Estudo de elementos dos games aplicados em Processos de ensino e aprendizagem. Dissertação (Mestrado em Educação) - Universidade de Caxias do Sul, Rio Grande do Sul, 2013.

FREIRE, J. B. O Jogo: entre o riso e o choro, Campinas, SP: Autores Associados (Coleção educação física e esportes). 2002

GEEKIE GAMES. Site Oficial. Disponível em: <https://geekiegames.com.br>. Acesso em 10.jan.2018.

GIL, A. C. Como Elaborar Projetos de Pesquisa. São Paulo. Atlas. 2010.

GUIMARÃES, S. E. R. (Org.). Motivação para aprender. 1 ed. Petrópolis: Vozes, v. 1, p. 13-70, 2010.

HALLIDAY, M.A.K. An introduction to functional grammar. London: Edward Arnold,1994

HJORLAND, Birger. Epistemology and the Socio-Cognitive Perspective in Information Science. Journal of the American Society for Information Science and Technology, v. 53, n. 4, p. 257-270, 2002.

HUIZINGA, J. Homo Ludens: O jogo como elemento da cultura. São Paulo: Perspectiva, 2000.

INHELORA K. J.: Uma Introdução ao Pensamento de Vygotsky, Revista Linhas, volume 3, no. 1, 2002.

KAPP, K.M. The gamification of learning and instruction: game-based methods and strategies for training and education. San Francisco: Pfeiffer, 2012.

KAPP, K.: Once again games can and do teach, 2013. Disponível em $<$ http://www.learningsolutionsmag.com/articles/1113/once-again-games-can-and-\%20do-teach> Acesso em 10.jan.2018.

KHAN ACADEMY. Site Oficial. Disponível em :<http://www.khanacademy.org.> Acesso em 10.jan.2018.

KLOCK, A. C. T.; CARVALHO, B. E. R.; GASPARINI, I. Análise das técnicas de Gamificação em Ambientes Virtuais de Aprendizagem. RENOTE: Novas Tecnologias na Educação. V. 12, n. 2, 2014. Disponível em:

$<$ http://seer.ufrgs.br/index.php/renote/article/view/53496>. Acesso em 10.jan.2018.

KRESS G.; Van LEEUWEN. Multimodal discourse: the modes and media of contemporary communication. London: Hodder Arnold Publication. 2001.

LILICH, I. A Sociedade sem Escolas. São Paulo: Vozes, 1985.

LIU, Y., A., T., Nakajima, T. Gamifying Intelligent Environments. Ubi-MUI '11 Proceedings of the 2011 international ACM workshop on Ubiquitous meta user interfaces. Scottsdale, Arizona, USA, 2011.

LUNA, T. S. A pluralidade de vozes em aulas e artigos científicos. Revista Ao Pé da Letra (UFPE), v. 4, 2002.

MARTINS, D. R.; MUNHOZ, A. S. Gamificação: Perspectivas de Utilização no Ensino Superior, 2014. UNINTER. Curitiba/PR. Disponível em: <http://www.abed.org.br/hotsite/20-ciaed/pt/anais/pdf/91.pdf>. Acesso em 10.jan.2018.

McGONIGAL, J. Realidade em jogo: por que os games nos tornam melhores e como eles podem mudar o mundo. Rio de Janeiro: Best Seller, 2012.

MUNTEAN, C. I. Raising engagement in e-learning through gamification. University of Bucharest and "Babes-Bolyai" University of Cluj-Napoca, 2011.

NANCI, C. Gamificação: verdades, mitos e questões em aberto. Disponível em < https://agoraentert.com.br/insights/gamificacao-verdades-mitos-e-questoes-em-aberto/>. Acesso em 10.jan.2018.

NAVARRO, G. Gamificação: a transformação do conceito do termo jogo no contexto da pós-modernidade. Trabalho de conclusão do Curso de Especialização (lato sensu) em Mídia, Informação e Cultura. Universidade de São Paulo, São Paulo, 2013. 
ORRICO, A. Mercado brasileiro de games já é o quarto maior do mundo e deve continuar a crescer. O Estado de São Paulo, São Paulo. Disponível em:<http//www1.folha.uol.com.br/tec/1165034-mercado-brasileiro-de-games-ja-e-o-quarto-maiordo-mundo-e-deve-continuar-a-crescer.shtml>. Acesso em 10.jan.2018.

PAPERT, S. A máquina das Crianças: Repensando a Escola na Era da Informática. Trad. Sandra Costa. Porto Alegre: Artmed, 1994.

PIAGET, J. Epistemologia genética. 2. ed. São Paulo: Martins Fontes, 2002.

PINHEIRO, L.V. Fronteiras e horizontes da pesquisa em ciência da informação no Brasil. IBICT, 2013.

VIANNA, Y.; VIANNA, M.; MEDINA, B; TANAKA, S. Gamification, Inc.: Como reinventar empresas a partir de jogos. MJV Press: Rio de Janeiro, 2013

WERNECK, V. R. Sobre o processo de construcão do conhecimento: o papel do ensino e da pesquisa. Ensaio: aval.pol.públ.Educ.[online], vol.14, n.51, pp.173-196, 2006.

XAVIER, A. C. Como se faz um texto: a construção da dissertação argumentativa. Catanduva: Rêspel, 2006.

ZICHERMANN, G.; CUNNINGHAM, C. Gamification by Design: Implementing game mechanics in web and mobile apps. Canada: O’Reilly Media Inc., 2011.

\section{Dados dos autores}

Tomás Roberto Cotta Orlandi

Doutorando em Ciência da Informação pela Universidade de Brasília.

tomasroberto@gmail.com

\section{Claudio Gottschalg Duque}

Professor do Programa de Pós-graduação em Ciência da Informação da Universidade de Brasília (PPGCINF/UNB).

klaussherzog@gmail.com

Alexandre Mori Mori

Doutorando em Ciência da Informação pela Universidade de Brasília. xmorihome@gmail.com

\section{Maria Tereza de Andrade Lima Orlandi}

Especialista em Educação pela Universidade Católica de Brasília. mte.orlandi@gmail.com

Recebido - Received: 2017-04-05

Aceitado - Accepted: 2018-01-23

\section{(cc) EY}

This work is licensed under a Creative Commons Attribution 4.0

United States License.

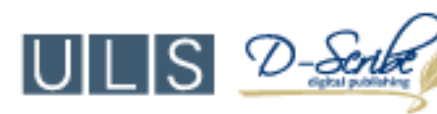

This journal is published by the University Library System of the University of Pittsburgh as part of its D-Scribe Digital Publishing Program and is cosponsored by the University of Pittsburgh Press. 